\title{
Correction to: Wives' gender identity, work hours, employment status, and life satisfaction: evidence from Japan
}

\section{Jun Ando ${ }^{1}$ (D)}

Published online: 29 December 2020

(C) Japan Economic Policy Association (JEPA) 2020

\section{Correction to: International Journal of Economic Policy Studies https://doi.org/10.1007/s42495-020-00052-z}

In the original publication of the article, the acknowledgment was incorrect. The correct acknowledgment appears as below.

The data for this secondary analysis, "Survey Concerning Social Life and Time Budget 2007, JTUC Research Institute for Advancement of Living Standards (RENGO-RIALS), Japan," were provided by the Social Science Japan Data Archive, Center for Social Research and Data Archives, Institute of Social Science, The University of Tokyo. I acknowledge Yasuhiro Tsukahara (Meiji University), Toru Yarita (Nagoya University of Commerce \& Business), Takashi Nagatomi (Kokushikan University), and the anonymous referees of International Journal of Economic Policy Studies for their helpful comments. Finally, I thank the Niigata University of International and Information Studies for fnancial support. We would like to thank Editage (www.editage.jp) for English language editing.

Publisher's Note Springer Nature remains neutral with regard to jurisdictional claims in published maps and institutional affiliations.

The original article can be found online at https://doi.org/10.1007/s42495-020-00052-z.

Jun Ando

j-ando@bukkyo-u.ac.jp

1 Department of Public Policy, School of Sociology, Bukkyo University, Kyoto City, Kyoto, Japan 